\title{
Analgosedation during transcatheter aortic valve implantation: Review and protocol at University Hospital Centre Split
}

\section{(D)Andrija Matetić1 ${ }^{*}$, DMarija Romić', (DNikola Crnčević', DIvica Kristić', (D) Vjekoslav Tomulić ${ }^{2}$, (D)Frane Runjić1}

'University Hospital Centre Split, Split, Croatia

2University Hospital Centre Rijeka, Rijeka, Croatia
RECEIVED:

July 30, 2021

ACCEPTED:

August 5, 2021

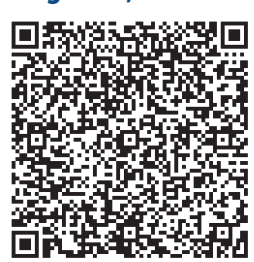

KEYWORDS: analgosedation, transcatheter aortic valve implantation, propofol. CITATION: Cardiol Croat. 2021;16(9-10):293-4. | https://doi.org/10.15836/ccar2021.293

*ADDRESS FOR CORRESPONDENCE: Andrija Matetić, Klinički bolnički centar Split, Spinčićeva 1, HR-21000 Split, Croatia. / Phone: +385-98-954-6455 / E-mail: andrija.matetic@gmail.com

ORCID: Andrija Matetić, https://orcid.org/0000-0001-9272-6906 • Marija Romić, https://orcid.org/0000-0002-7683-2837 Nikola Crnčević, https://orcid.org/0000-0002-1399-3406 • Ivica Kristić, https://orcid.org/0000-0002-9882-9145 Vjekoslav Tomulić, https://orcid.org/0000-0002-3749-5559 • Frane Runjić, https://orcid.org/0000-0001-6639-5971

\section{|I||||||||||||||||||||||||||||||||||||||||||||||||||||||||||||||||||||||||||||||||||||||||||||||||||||||||||||||||||||||||||}

Background and aims: Periprocedural analgosedation during transcatheter aortic valve replacement (TAVR) has evolved significantly over the past decade. First procedures were done in general anaesthesia under the supervision of an anesthesiologist, while recent trends suggest periprocedural analgosedation performed by interventional cardiologists/TAVR operators ${ }^{1}$. This method often includes different medications and protocols, depending on the site-specific preferences. Here we present a review of propofol effects along with the protocol utilized at the Catheterization Laboratory (Cath Lab) at the University Hospital Centre Split.

Review and protocol presentation: Our primary used anaesthetic medication is propofol due to its beneficial pharmacologic properties including short action and titratable effects leading to effective sedation with amnesia, well-being and anti-emesis ${ }^{2}$. In addition, it shows a good correlation with bispectral index (BIS) allowing for easier titration during longer procedures. However, due to its insufficient analgesia, we utilize high dose-volumes of local anaesthetic and optionally a systemic bolus-doses of fentanyl in selected individuals (Figure 1). To this date, this protocol provided a safe, effective and reproducible periprocedural analgosedation during TAVR. Importantly, this protocol was successfully performed by the Cath Lab Team, without the need for additional healthcare resources or staff allocati$\mathrm{on}^{3}$. To avoid large radiation to the staff, we have also adjusted the equipment (use of long intravenous lines; rotation of X-ray tube; monitor orientation) and modified the staff position (Figure 2).

Conclusions: In conclusion, there are different regimens for periprocedural analgosedation. Periprocedural analgosedation with propofol in the bolus-continuous infusion scheme proved to be safe, effective and reproducible during TAVR. Interventional cardiologists and specialized Cath Lab team are trained to provide all aspects of management and care to these patients.
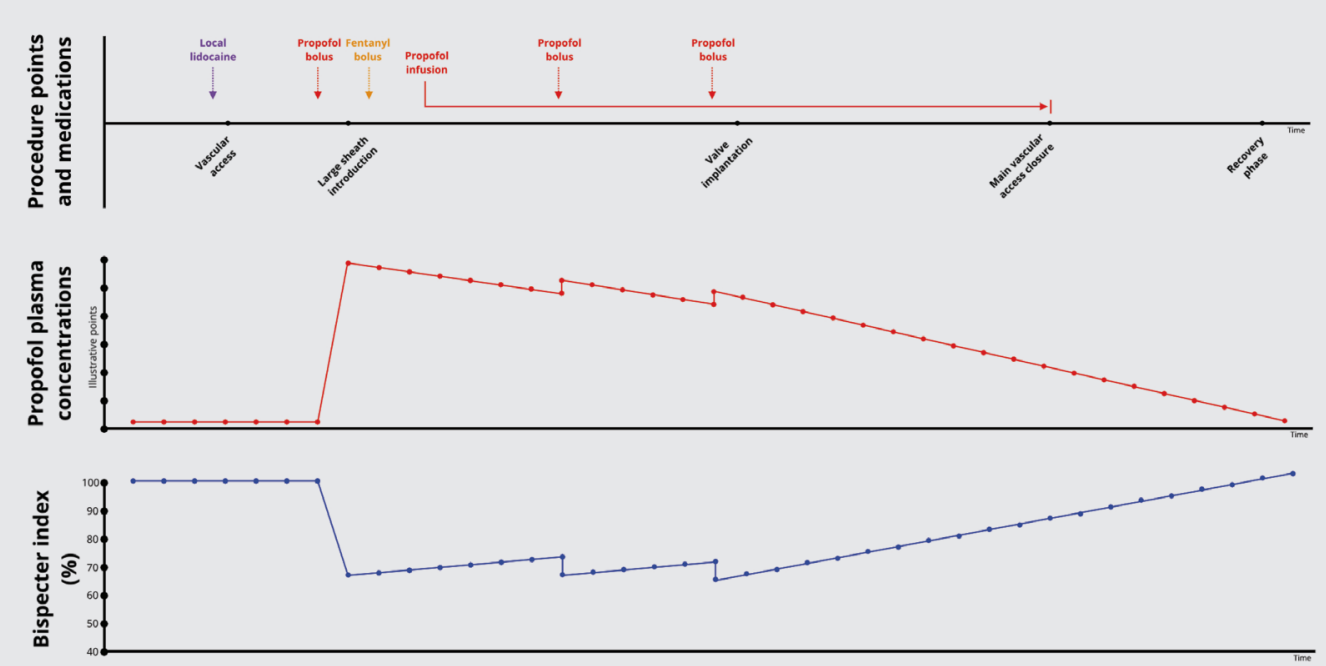

FIGURE 1. Illustrative overview of propofol plasma concentrations and bispecter index in relation to procedural phases (Split protocol). 


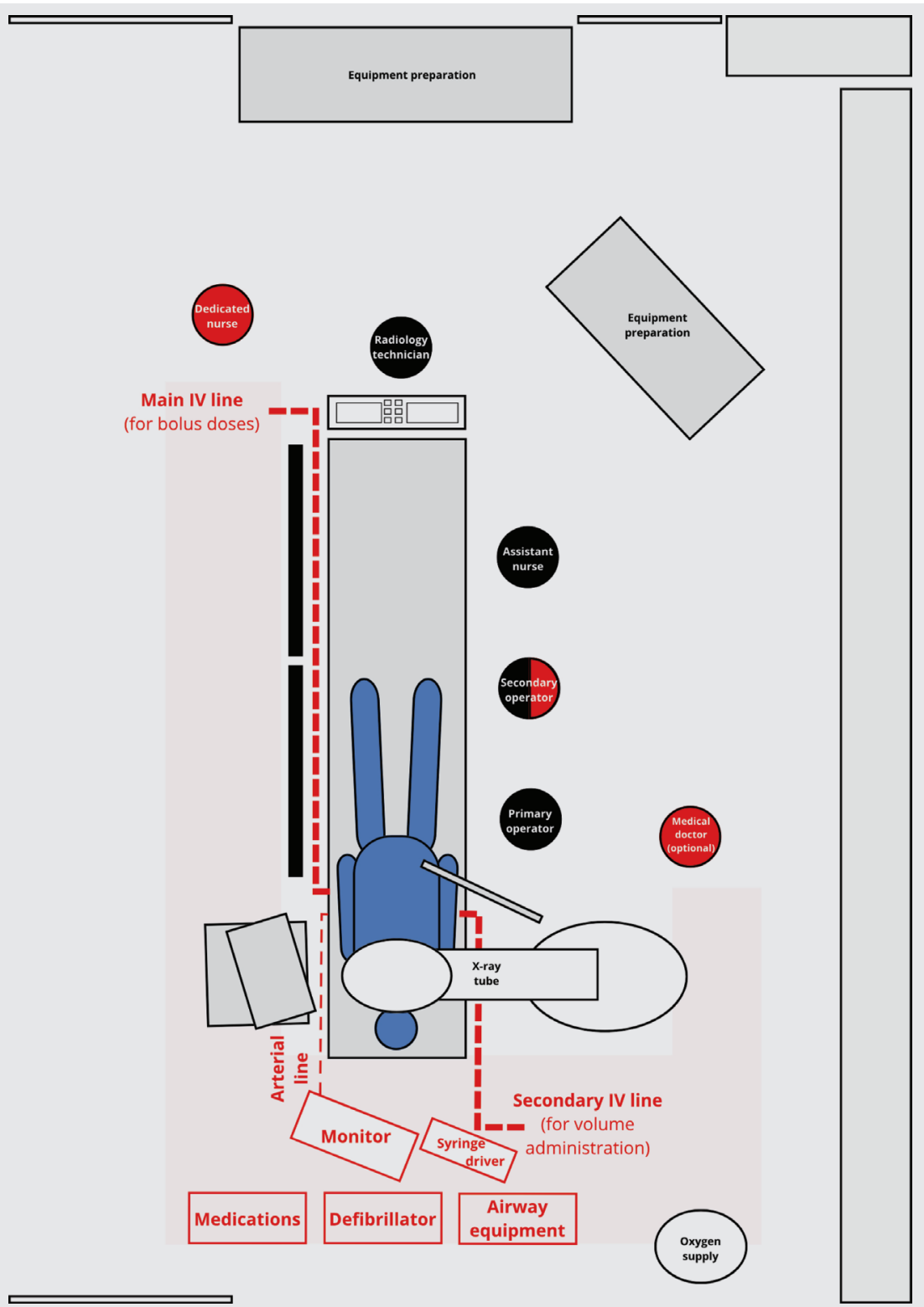

FIGURE 2. Schematic layout of the equipment/staff in the Cath Lab with regard to analgosedation.

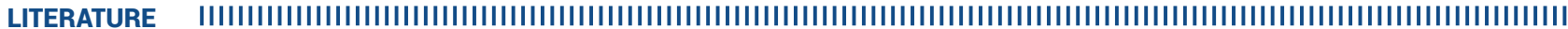

1. Mayr NP, Michel J, Bleiziffer S, Tassani P, Martin K. Sedation or general anesthesia for transcatheter aortic valve implantation (TAVI). J Thorac Dis. 2015 Sep;7(9):1518-26. https://doi.org/10.3978/.jissn.2072-1439.2015.08.21

2. Sahinovic MM, Struys MMRF, Absalom AR. Clinical Pharmacokinetics and Pharmacodynamics of Propofol. Clin Pharmacokinet. 2018 Dec:57(12):1539-1558. https://doi.org/10.1007/s40262-018-0672-3

3. Khalil M, Al-Agaty A, Asaad 0, Mahmoud M, Omar AS, Abdelrazik A, et al. A comparative study between propofol and dexmedetomidine as sedative agents during performing transcatheter aortic valve implantation. J Clin Anesth. 2016 Aug;32:242-7. https://doi.org/10.1016/j.jclinane.2016.03.014 